\title{
50th Anniversary Paper A commentary on Mellor and Tocher: A steel-works production game
}

\author{
RJ Paul \\ Brunel University
}

As an enthusiastic simulationist for many years, whilst I admire a great many other simulationists of greater fame and too numerous to mention, my British hero has always been Keith Tocher. Here was a researcher/practitioner who in his seminal book The Art of Simulation ${ }^{1}$ both encapsulated the nature of the subject in the book's title, but also wrote about many things that were later claimed by others as original discoveries. So when asked to find a suitable anniversary paper for this Special Issue and write this covering piece for it, I hoped to find something appropriate by Tocher.

Ranyard $^{2}$ in his history of OR and Computing gives an extensive coverage of early simulation, including much of the seminal work by Tocher ${ }^{3}$. However, much of this work was not published in the Operational Research Society's journal-except the paper reproduced in this issue by Mellor and Tocher. This paper has much to commend it, as I shall now explain.

At first sight, this paper merely reports on another simulation game, which nowadays are two-a-Euro. However, whilst the paper is admirably brief, clear and concise (the antithesis of a modern research paper some might think), it contains a number of lessons that appear to be still being learnt.

The production game concerned 'the development of continuous central control, based on a scheduling system which would ensure that the idle times at the (steel) mills was minimized, and that casts of steel of the correct types to meet an order book were supplied'. The model, which was written in the General Simulation Program (GSP) language, fed information to and took instructions from the scheduler - an early man-in-the-loop simulation!

There were several objectives to the gaming sessions. The first was to validate the simulation model by comparing its behaviour with that of the real plant under present conditions. With the help of plant management, the model was accepted during the early sessions as valid for the assessment of the value of control systems - user participation demonstrated at a very early date! The second objective, after the model gained acceptance (i.e. the stakeholders agreed a common understanding in modern parlance) was to estimate the efficiency of any control system by comparing its performance with that of experienced human controllers. In other words enabling the game to become an expert system for training inexperienced human controllers. The third objective of the game was to demonstrate the advantages of continuous central control, which led to the acquisition of a suitable computer by the works for doing this.

The conclusions bear quoting: 'This success was only achieved by the involvement of the plant management in the development of the model, by the demonstration of the value of presenting full information to controllers who were responsible for the co-ordination of activities throughout the plant, and by familiarizing them with the techniques of control by computer.' These lessons on how to apply simulation/OR resonate today. It is worth remembering that this sort of success could be found well before the myriad contributions claimed by soft modelling approaches (see, for example, Rosenhead ${ }^{4}$ ) a quarter of a decade later relative to so-called 'traditional approaches'.

\section{References}

1 Tocher KD (1963) The Art of Simulation. English Universities Press, London.

2 Ranyard JC (1988). A History of O.R. and Computing. J. Opl. Res. Soc. 39: 1073-1086.

3 Mellor P and Tocher KD (1963) A steel-works production game. Opl. Res. Q. 14: 131-135.

4 Rosenhead J editor (1989). Rational Analysis for a Problematic World. John Wiley, Chichester. 